\title{
The Value of Image. The Design of and Data Streams from the Perception by Design ${ }^{\dagger}$
}

\author{
Fabio Bianconi, Alessandro Buffi, Maria Pia Calabrò and Marco Filippucci * \\ University of Study of Perugia, Via G. Duranti, 93, 06125 Perugia, Italy; fabio.bianconi@unipg.it (F.B.); \\ buffi92@gmail.com (A.B.); mariapia.calabro@libero.it (M.P.C.) \\ * Correspondence: marco.filippucci@unipg.it; Tel.: +39-349-390-3650 \\ + Presented at the International and interdisciplinary conference IMMAGINI? Image and Imagination \\ between representation, communication, education and psychology, Brixen, Italy, 27-28 November 2017.
}

Published: 24 November 2017

\begin{abstract}
The importance of design aimed to the enhancement of the urban landscape, it is accredited by the eye-established preeminence in today's culture. Image and form are essential elements of the perceptual process and they are closely linked to sight, the sense responsible for the reproduction and organization of the built. The education to vision, the interpretation of the transformations and awareness of the design process are the issues that schematize the purpose of the research, geared to restore the value of perceptual space. The processed data analysis parametrically becomes project ideas focused on the relation between the flows that characterize the relation with places and influenced by the dynamic exploration of the subject.
\end{abstract}

Keywords: picture of the city; smart city; perception

\section{Introduction}

The search path wants to analyze the centrality of the image and its reinterpretation from the perspective of the project design, making use of its ability to be an "operational program to learn and, at the same time, a set of interpretive assumptions made for an action strategy" [1] (p. 11).

Image and design, a relation focusing on their common essence of conclusive moment of a creative process, which begins with the impact of a reality and develops into "an intellectual elaboration that takes form through the figuration, and then it lives as an autonomous reality and as time communications tool" [2] (p. 9). The image is correlated linearly to view, "with the senses that are windows on the world, the ways of the latter access within us" [3]. This dialogue between man and reality is always adjusted by the five senses, each of which offers types of differentiated knowledge later integrated and mixed in order to build reality itself. View has been since in the past the privileged sense as the main source of wealth of information. The education to vision, the interpretation of transformations, the knowledge of design process, are the three basic steps that can outline the purpose of this research. "See", writes Arnheim, "it consists in grasping the structural elements instead of in the record indiscreetly all details" [4] (p. 82); "see," writes Kepes, "it is first and foremost a tool for orientation, a means to evaluate and organize spatial events "[5] (p. 17)," to orient themselves not only physically but also humanly" [5] (p. 18). Vision is then understood as a process that "organizes and synthesizes the complete structure detected by particular optical images" [6] (p. 128).

Since the inception of culture in the classical world, the scientific research [7] and artistic representation [8] (p. 93) focused on the value of the vision, this proposes and organizes the building. This is evident in the temples position, which, according to Vincent Scully, manifests a true and proper "placement strategy" in a landscape that changes the direction [9] passing from "qualitative and hierarchical forms" to "homogeneous and reversible" [10] (pp. 159 et seq.). This process, to 
arrange in accordance with the vision, it is finalized, taking the words of Heidegger, to "grasp the organized nature as a set of calculable forces" and to "put in place in vision of the use" though "the accuracy of representation “[11] (p. 198).

The quality of architecture is related to the role of vision and representation, as evidenced by the representative studies of Constantinos Doxiadis (Figure 1) on the Parthenon [12], which according to Le Corbusier, is the architecture paradigm, but even more a "decisive moment for architecture" [13] (p. 180); "the purest witness of the sensations' physiology".

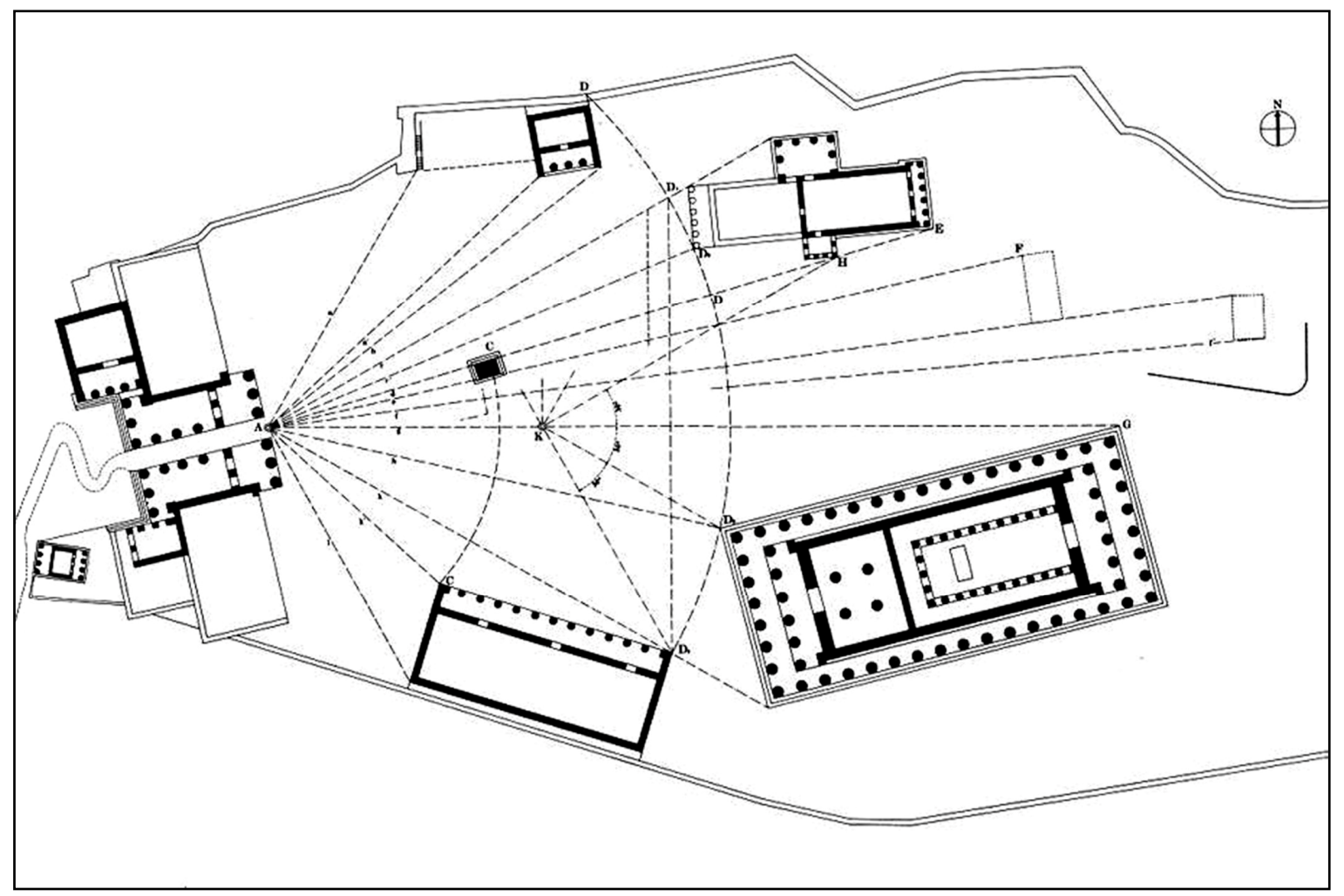

Figure 1. The central eye in the Greek space according Constantinos Doxiadis.

In the statement that "the view of object is visible" [14], it is defined the limit of the field of interest in what it is not perceptible with other senses. The development of sensitive knowledge takes place, according to the same Aristotle, in two stages: in the first ("impression of the senses") the sense organ "includes" passively (without matter) the shape of what is observed and the sense "feels" the sensible; in the second development of sensitive knowledge it intervenes the sensus communis that coordinates the senses and provides awareness of the sensation [15]. If the five senses were completely independent from each other, not coordinated and integrated, we would not be able, for example, to perceive the roughness with the view, or either to perceive a fabric with both view and touch. The sensus communis integrates and unites the five senses and, with the help of the imagination (phantasia, production of images), memory (storing images) and experience (accumulation of sensations), they distinguish, recognize, judge, compose images impressions of the senses [16].

This interpretative process can be translated into a valid research method to analyze the image of the city. The first phase of the research on landscape is linked to impression, it includes the correspondence between landscape and icon. Deconstruction then imposes the relation with similarities, sectioning of the totality into categories, so that from all the observations it is possible to extrapolate a law. Finally, the construction of indices, is the scientific action that puts the replacement of complex reality with a synthetic interpretation able to simulate reality and replace it. This phase corresponds to the final replacement of parts (and not of "pieces") [17] (p. 194), in order to arrive to the symbolic representation, the result of the cultural substrate originated from observations and codes, a conversation between reality and model aimed to abstraction, but linked to subjectivism, 
because every gaze involves an assessment and a comparison, according to Kant the difference between perceptual judgment and empirical judgment [18] (p. 11).

It thus introduces the analysis of relation between image and inflected forms, subject of the American architect Kevin Lynch's researches in the 60's [19] (pp. 479-486). Placed in the center of the drawing, the image of the city assumes the vision of the aggregates as a unitary structure, then not only a simple concentration of events, but the product of interpretable signs according to their order. In this context Lynch introduces the "figurability", defined as "shape, color or arrangement that simplifies the formation of environmental images vividly identified, powerfully structured, highly functional" [20]. It is possible then to analyze then the essential elements of perception, to turn them into useful data for the project, to identify focal points with which organize the perceived, divided into regions before and reconnected to memorable itineraries [20] (p. 29). In their composition, the basic algorithms of drawing, point and line, emerge as the protagonists of the schematization synthesis [1] (p. 18), as the two-dimensional drawing.

Points and lines alternate because "continuous activity consumes nervous energy. In its work, the eye needs a lot of action and rest" [5] (p. 57). It opens then the orientation of the subject, the freedom of the conquest of space that is through knowledge, the action that discovers an order. Mostly a mental action, referenced from the observer and based on polarity and meanings: to identify cannot be separated from identifying oneself, and recognition allows the creation of a "logical geography" which shows the value of the sign, which is central both in perception and in the subsequent design phase for the bond that exists between interpretation and meaning.

But, as well analyzed by Roland Barthes, "meanings are like mythical beings, extremely labile, which always, eventually, at some time, act as signifiers of something else: the meanings cease, the signifiers remain. Hunting for meaning can only be, therefore, a provisional meaning" [21] (p. 13). The wealth of meaning in our cities, always plural, never unified, it opens to almost psychoanalytic courses aimed to dig in the image for better understanding and it forms increasingly experiences the sense of identity of the place.

It is in this logic that connects the need for participatory approaches, aimed at circumventing the risk of subjectifications, sometimes to understand the jumble of signs the "aesthetic significance (which is not the aesthetic value): servant or not for practical purposes, be it good or bad, it demands to be the object of an aesthetic experience" [22] (p. 13). The modern city has become a media and architectural complex at the same time. It is a place where the virtual production of urban space has become the constitutive frame of a new mode of social experience, it seems regardless of the relational abstract physical relation, it is defined as "a space that has been emptied of quality that is felt to be changeable, variable and contingent" [23].

The importance given to the individual lies in the belief that there is a reality of it until it is not done by someone experienced [24]. The readability of a city, its visual impact, the ability to provide distinctions and relations with the observer, is a variable whose study allows to understand many problems [20].

\section{Case Study}

The analytical and the objectivity of the perceived data, understood in the relation eye-built on one hand and on the other hand the need of intersubjectivity, which opens in the sense of participative, are the two fundamental reasons for the choice taken in case for the present design study.

The area identified is the Perugia's "Percorso Verde", Green Path (Figure 2), one of the largest and frequented urban parks of the city, characterized by a strong sense of ownership by the citizens. Its length is about $3 \mathrm{~km}$, and it covers most of the Ferro di Cavallo district, on the western outskirts of the city. 


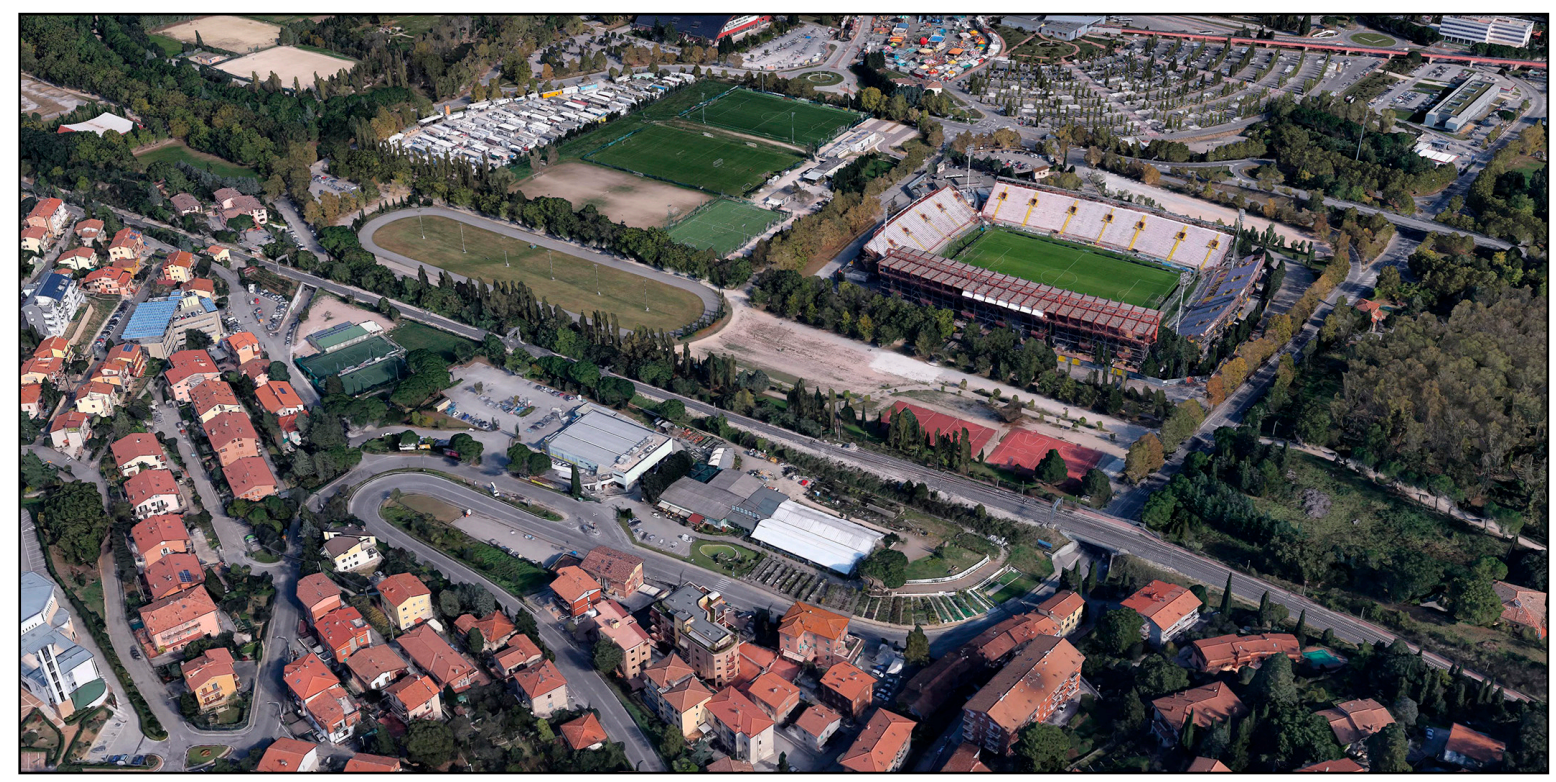

Figure 2. Perugia's Percorso Verde_Ferro di Cavallo District.

The name of the neighborhood derives from the particular shape of a horseshoe, which takes the road that passes through the bottom, the Trasimeno West.

Compared to the system of the early twentieth century the change that stands out most is the one related to the increase of the section of the said road, in correspondence with the rail underpass that nothing has retained its original appearance. The work of art, in concrete, has in fact taken the place of that to bow made with Lacugnano stone quarry, in the implicit anonymity, depleting the value of the "works of art" [25].

Along Trasimeno West Street, it extends the project area, now destined to the practice of outdoor sports and equipped with jogging tracks, a cycle trak and several basketball courts. Adjacent to the Percorso Verde there are located the municipal stadium Renato Curi (1975), the PalaEvangelisti (1984) and the Borgonovo center (2008). The presence of these important active and functional centers of the neighborhood is one of the most crowded and socialization places of the city. Their design, however, being taken place at different times and gradually to meet the current needs of citizens, today lacks of continuity and cohesion between the various elements.

The criticality, and the enhancement potential inherent in place, has been design the object of the intervention, aimed to the realization of new identity spaces, the reconnection of the places and the realization of a dialogue between them, starting from the redesign of the connections of the various green areas from the exploitation of those residual, and the design of a pedestrian network, harbinger of greening solutions.

The nature area in the urban landscape appears as a fragmented remnant [26], an unresolved place [27] and removed [28], "Third Landscape" [29], partly insecure, of all essential elements for an urban mending that finds in the ecological centrality also a cultural model, to live with new responsibility and involves urban space [30]. The strategy that can be appealed to "pervasion of the Green", has the aim to promote resuming places: identity and identification [31] become the characteristics conform from which it is possible to achieve innovative management solutions based on participation, joint planning, involvement and social cohesion, in order to ensure long-term sustainability of interventions [32] (pp. 313-320).

\section{Materials and Methods}

\subsection{Finding Participated Data}

The starting point for the design of the landscape is the perception of citizens on the public space in question, the processing time to understand how they live and see the city, beyond the differences that make "unique" each subject from the others. Perugia's Percorso Verde, the project area, was 
walked all around with the eyes and senses of those who live it, in order to perceive the overlapping of spaces, materials, lights, and get to have a complete knowledge of it, to enhance its identity, its potential and solve the critical issues. The look that leaked from the interpretation of the place, it became the project guide.

To apply the guiding idea of figuration to the public space in question, there were used during the search two methods: a sample of citizens were interviewed on the image they possessed of the environment and later it was asked them to make that image real with a drawing. The main request was to sketch out a map of that part of the city, to describe on it a number of routes, cycle and pedestrian and vehicular traffic, and briefly describe the elements perceived as the most distinctive and vivid in the subject's mind [20]. This method was chosen to test the hypothesis of figuration, to obtain an approximation of the image of the city, to compare it with the image resulting from the onsite visit and contribute to the development of suggestions for urban design.

The path of inquiry on the Percorso Verde, covered a sample of 100 individuals and for the nature to be balanced and consequently able to give a fair assessment of functional structures within the project area, it was decided to ask questionnaires to four distinct groups of people, each divided into equal number and age. As for the origin, it was only included in the survey the residents in the area of Perugia, for a fundamental requirement of the research is the knowledge of the place given by its frequency.

From the analysis, very important data on the identification of the place have emerged about the sense of direction that appears while walking through it and its strengths and weaknesses.

Another cognitive tool, used in the initial phase of the work, has been to design a drafting of mental maps, drawn by each respondent and depicting the staff of the mental representation under consideration. Using this tool, gave a graphical representation corresponding to the individual way of enjoyment of the park.

Mind maps are graphical representations of knowledge, based on the ideas of Tony Buzan, a cognitive psychologist, that allow to make quick associations around a central concept. They are very popular thanks to their simplicity of application that uses images, symbols, colors and thickness of the lines to highlight and characterize the various elements. The aim is to implement visual memory and then storing certain concepts [33].

The realization model of mental maps is essentially associationist, it was asked to proceed dynamically inserting and recombining elements in the map, using a hierarchical-associative structure and applying mental association process.

The data tools available to generate the typical hierarchical structure were points, which indicate the districts, the main identity spaces, secondary and criticality, and lines of different thickness in order to distinguish the driveways from those cycle-pedestrian and identify insurmountable limits, such as railways and rivers. The graphics chosen once again is the issue of the basis of design algorithms, the protagonists of the synthesis of the schematic design [34] and replicated in a second phase of the project in a parametric environment.

Such a mental association process has had a positive response in return of figuration of the space in question, it has allowed to understand what for its environmental images are vividly identified, powerfully structured and highly functional [20].

Mental maps resulting from the experimentation, in fact, have two connotations, some are found to be very consistent with real structure of the place, which makes it feel like a continuous system consisting of many interconnected parts; while others are characterized by missing parts and some confusion regarding the network of the paths, which reveals that some individuals experience of the place as fragmented. From the latter, it derives the most interesting design ideas aimed to give back to this public space, continuity resulting from the connection between its parts and the surrounding ones, and urban form similar to the one praised by Kevin Lynch: "easy to communicate, so clear and readable: in this way, the image of the city that you will get will have a meaning "[20].

To support this work, and to get a clearer idea about the use of the area and its inherent problems, in the questionnaire, it was investigated on three fundamental aspects for the representation of a public space: 
- the identity, in this issue we wanted to investigate the architectural and functional elements that enhance the individuality of the place, making it recognizable;

- orientation, aimed to identify the sense of orientation/loss that one feels inside the park;

- critical, concern the evaluation of the aspects regarding the usability, the recognizability, accessibility, maintenance, ecology and safety of the area.

The first group of questions, of a cognitive kind, where inherent the frequency, the mode of use of the project area and its recognizability, it provided information regarding most of the activities practiced therein, all the others interest a percentage lower or equal to $20 \%$. From the answers, it was possible to identify four main landmarks, spatial and architectural elements that qualify the area, such as the stadium, the basketball courts, the bowls and the green areas in general. The stadium is an external element to the area but it is perceived as if it was an integral part of it.

The general the feeling that prevails when someone is within the area is of a total orientation, due to the presence of several reference points. The $50 \%$ indicates the main one in the stadium, $30 \%$ of the basketball courts, $10 \%$ of the bowling and the cycle track. Walkways are rather numerous and confusing, especially in the area of the basketball courts, which is why the $80 \%$ of users always follows an of habitual travel path.

The main identified problems, however, appear to be related to the safety and maintenance of the area. The connection to the city center is guaranteed by the presence of the Mini-Metro Station adjacent to the Percorso Verde. Similarly, the two major sports centers Palaevangelisti and Borgonovo center are well connected with the area.

With regard to the latter, it is to be reported some problems concerning the interruption of the cycle-pedestrian network in Trasimeno West Street, whose crossing is currently governed by traffic light system, and the internal path that runs along a large green and fenced area.

Respondents have become an active part of the project, as proposing solutions to the critical reconnection of the cycle-pedestrian network by means of raised pedestrian crossing and the strengthening of the green system.

The material thus collected, was finally synthesized in a series of plants and relations to provide the fundamental public image of the survey area, correlated by its problems, visual qualities, elements and interrelations there between, providing details of the adjectives and the possible transformation.

In view of the centrality of the retrieval and interpretation of the data, the participatory design undertaken at the base of the present work, has been corroborated by a further collection of data obtained from the monitoring of the cycle-pedestrian flows and vehicular, related to the area of project, by installing devices Compact $1000 \mathrm{JR}$, and the relevant number of pedestrians or vehicles passing, date, time and traveling speed of the test section.

The analysis was developed, placing each device in correspondence of the three accesses to the green area, to monitor cycle and pedestrian flows, and one below the rail overpass in Trasimeno West Street, in order to have a relevant data concerning the traffic flow due to higher criticality. From monitoring for a period of 20 consecutive days, it was possible to identify the two times slots during which at the intersection in Trasimeno West Street there is the most significant interference between the two flows. The daytime band 11:00/13:00 vehicles arrive at about 1100 steps against the 400 the pedestrian-cycle, during the evening 17:00/19:00 it touches the first 1300 steps, the second approximately 150 (Figures 3 and 4). It appars the need to separate the flows, so as to convey them in preferential channels, thus avoiding interference and to conceal the presence of the railway line and the overpass felt as a margin between the park and the city. 


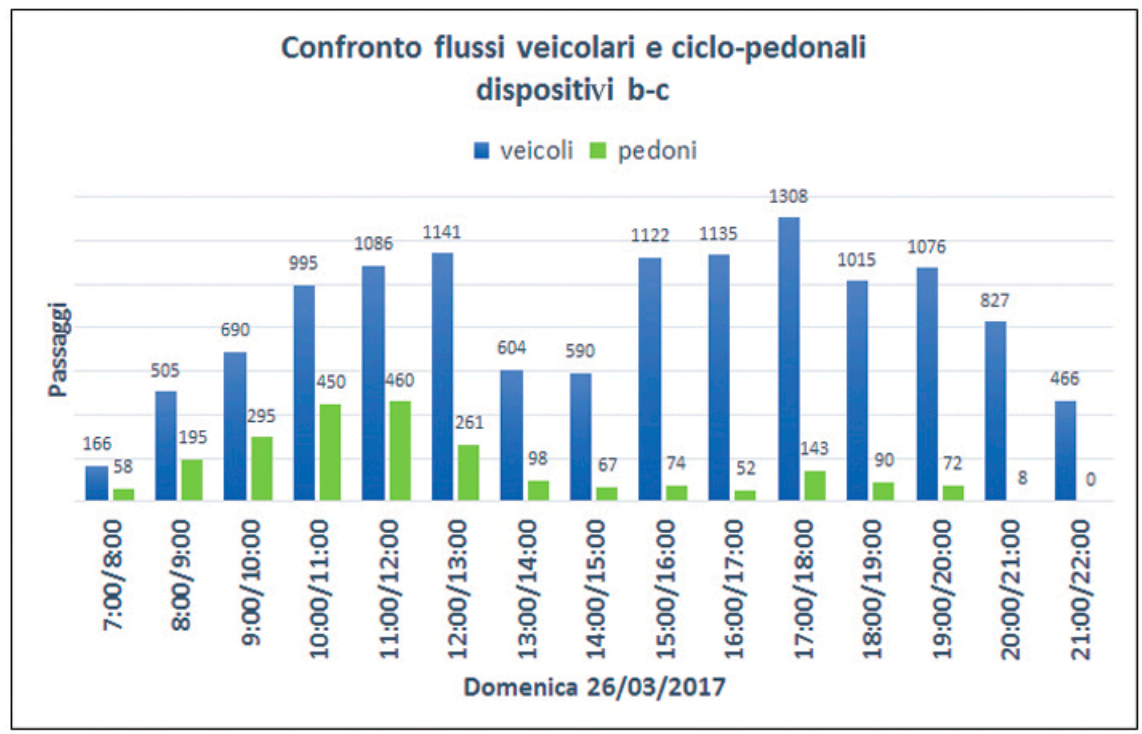

Figure 3. Comparison streams for time slots.

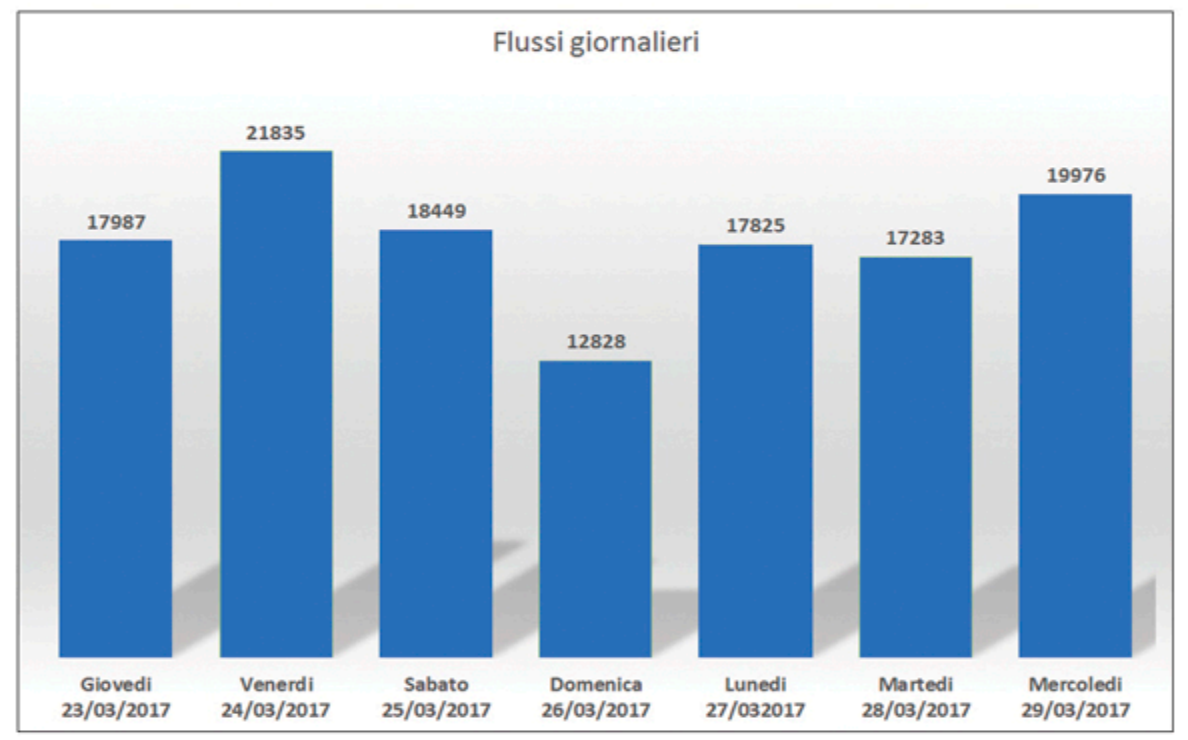

Figure 4. Flow daily vehicular.

This design phase falls within the second of the three states of the knowledge discussed by Alexander von Humboldt, the disarticulation of individual parts to get to extrapolate a law able to reassemble the unit in a new design synthesis. In support of this phase it is carried out a parametric experimentation based on terrain modeling based on the crossing streams. The importance of the latter is related to the subject of perception.

\subsection{Project Phase}

The analysis shows the need for a rethinking of the functions that defines new attractors: a sports area, a central square as a place to rest, to meet and directional choices and an area for children's exclusive use.

The data resulting from the analysis are transformed in the design assumptions that pose the center of the relation between flows and attractors, relation interpreted qualitatively through parametric and digital experimentation. These flows were processed as if they were moving forces along the main lines, they are represented by an actual or potential paths, crossing the area of which they change the geometry by changing the conformation of the ground. The parameterization force 
correlated to the computing capacity and therefore the possible comparison between solutions, theme that becomes the goal of problem solving. In the case study, in fact, the attractors explained in relation to the flows, it is possible to compare the different solutions and select the optimal one for design purposes.

At the base of such a dynamic, it has been studied and applied the operation of attractive curves and attractors points within a [34] system. In the case of architectural design, the attractors produce on space geometries, which are located in their field of action, the effects which change the behavior, making them move, re-orient, re-scaling (Figures 5 and 6).

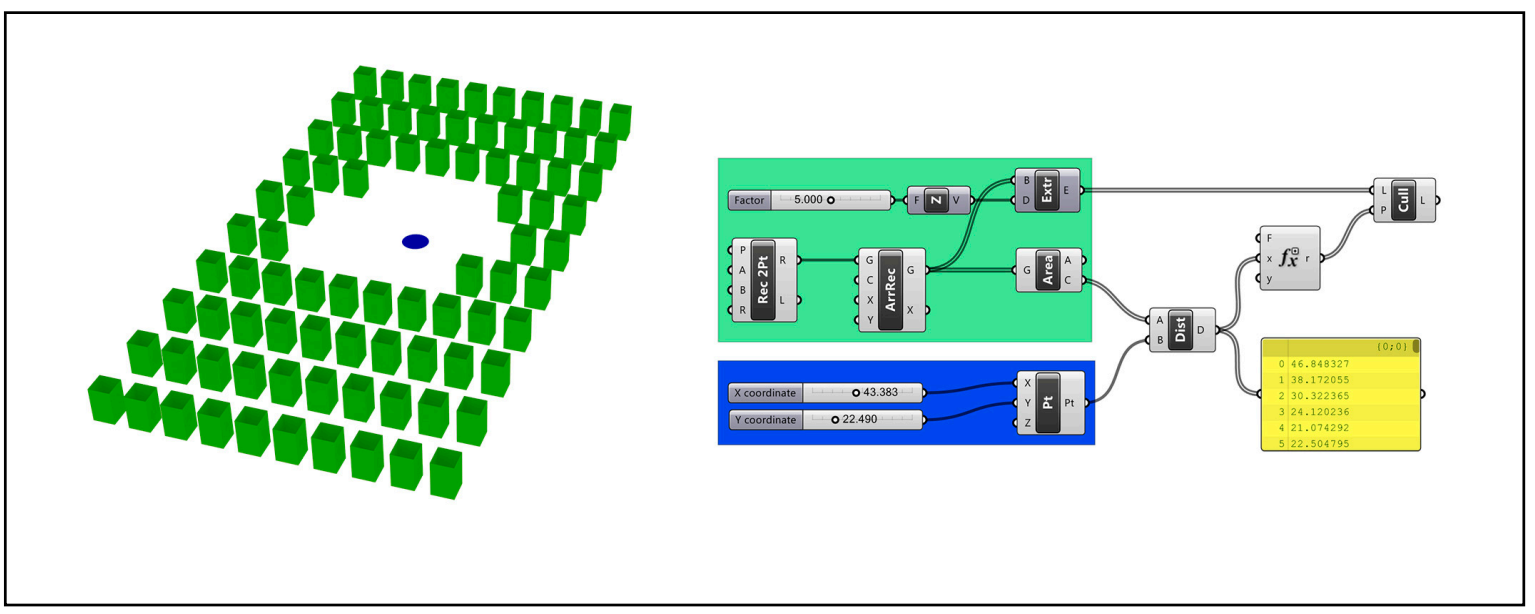

Figure 5. Attractor point.
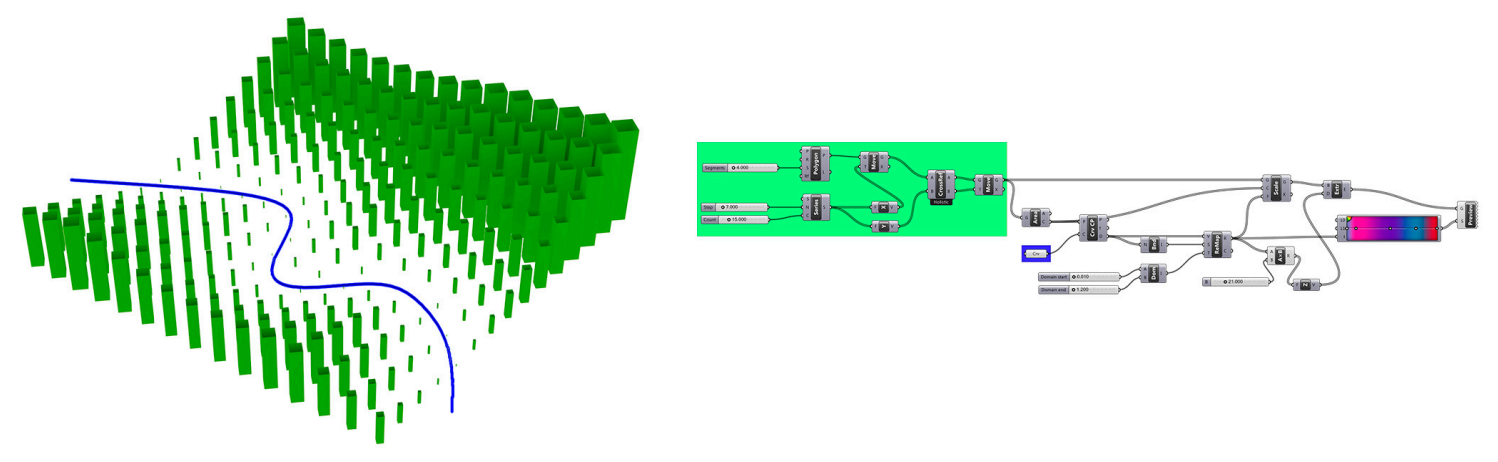

Figure 6. Attractive curve.

These changes depend on the mode of influence (e.g., distance) and by the power of the attractors themselves, both factors can be adjusted using specific parameters. The application of points attractors and attractive curves within the project area, suitably discretized into a grid made up of solids square shaped, it allowed to experience a terrain modeling to enhance the perception of the place as a function of view of its functional spaces. (Figure 7).

The objective is achieved by means of visual analysis based on precise parameters (Figure 8) that have been given as input: the analysis object geometry (functional spaces) and the representative of the context geometry (ground modeled); the process has returned in output a graded mesh representative of the degree of visibility of functional spaces from every point of the park (Figure 8). Among these, those with the best visual palatability, were considered optimal for the design of new cycle-pedestrian paths, replacing the existing ones, along which is the best possible perception of the park. 


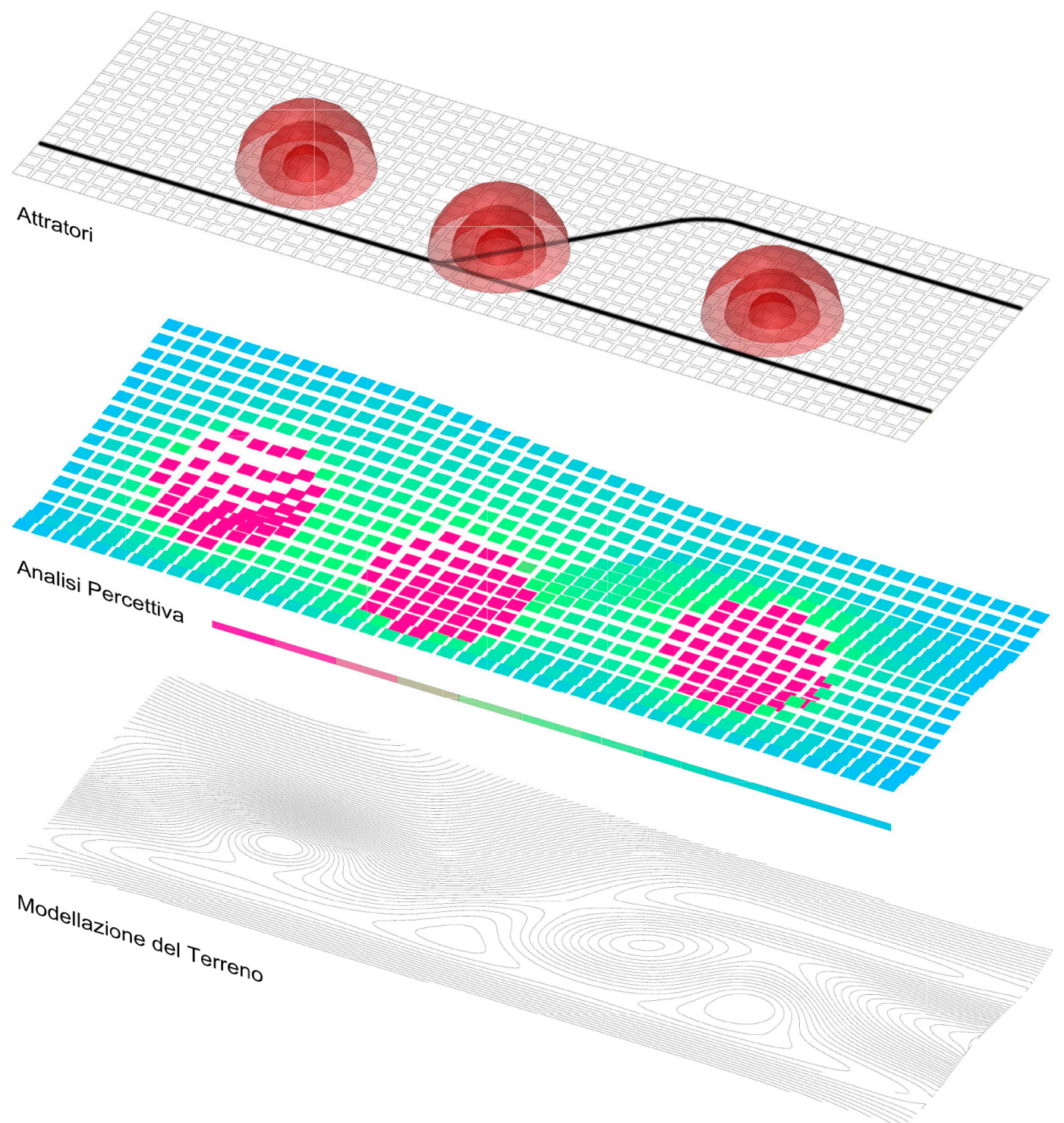

Figure 7. Perceptual analysis process at the base of terrain modeling by the use of attractors.

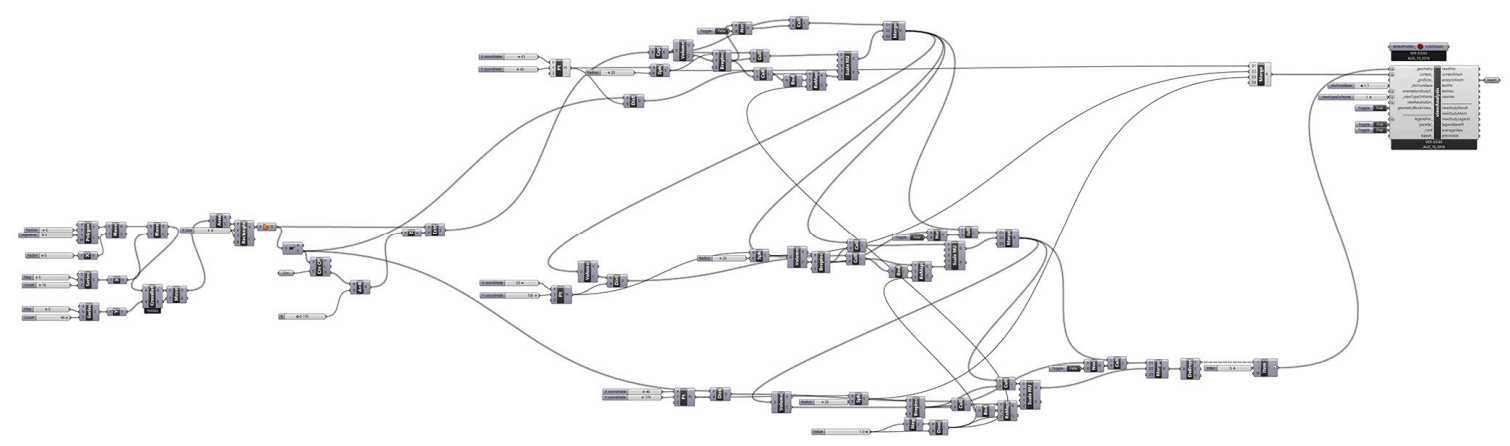

Figure 8. Perceptive analysis algorithm realized by means of plug-in Grasshopper "Lady Bug".

\section{Results}

The result of such a design is a public space completely retrained in its functions, deprived of critical points and moved with routes identified on the basis of the optimum degree of visibility (Figures 6 and 7).

The realization of the different objectives proposed (Figures 9 and 10), such as the restoration of the perceptual value of spatiality, education to the vision and awareness of the design process, are 
centered in the moment in which they relate also to the value and meaning, assumed by the path through the places over the time, the topic extensively analyzed in the early stages of this research.

Walking through landscape, especially when it is confused and disfigured in the mind of those who experience it, it may be useful to the deciphering of its meanings; it sharpens sight and other senses, it can give order and meaning to things among which we pass, and they have a clear and readable image of them. Walking physically in the places of our daily lives or mentally retrace it is then hired as a useful way to understand the territory, recognize it, map it, build it and live it. One method, this, who wants to be applicable to all the everyday places that need the perceived organization and a better definition of the relation between image and form.

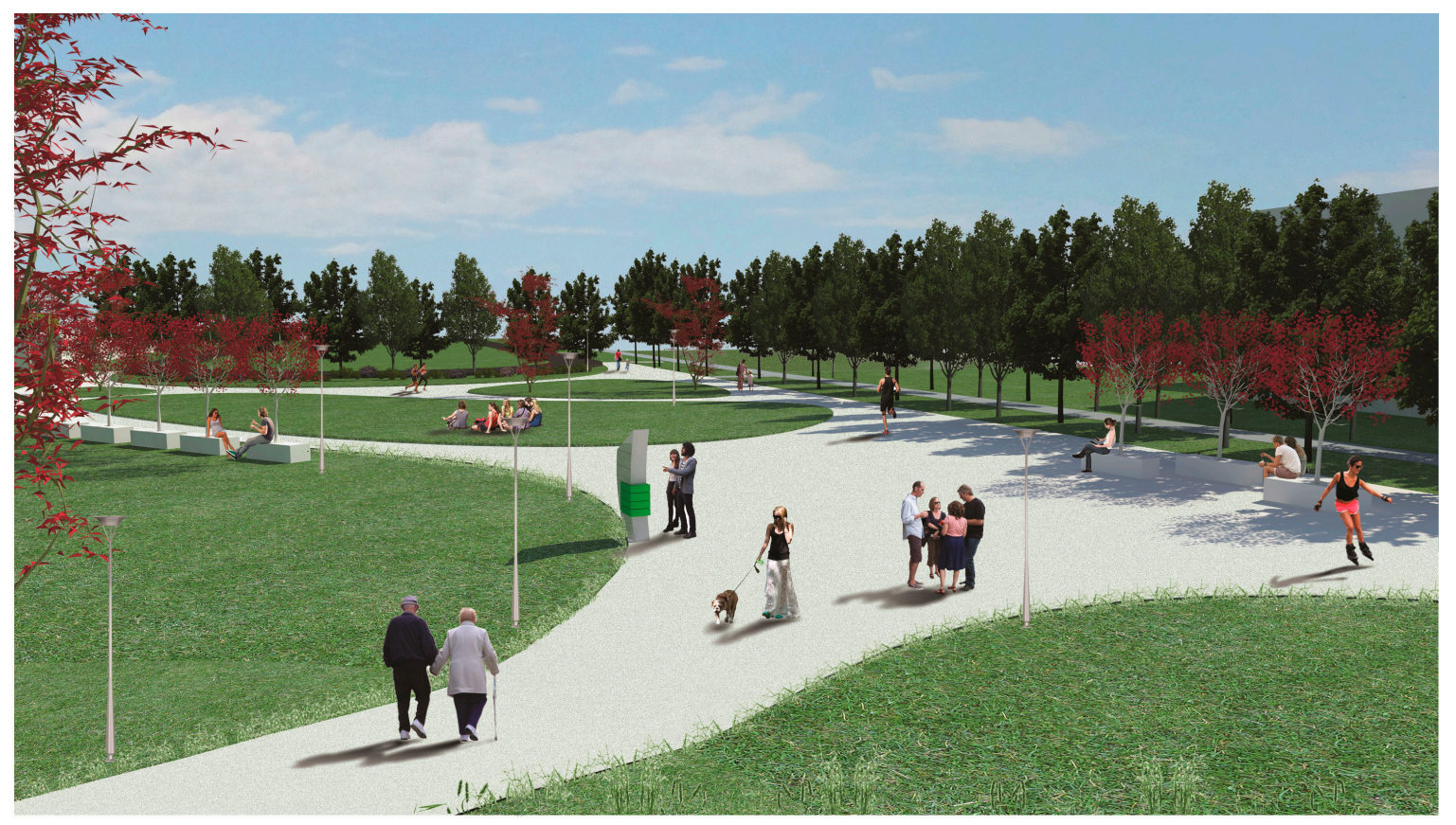

Figure 9. View of the central part of the park.

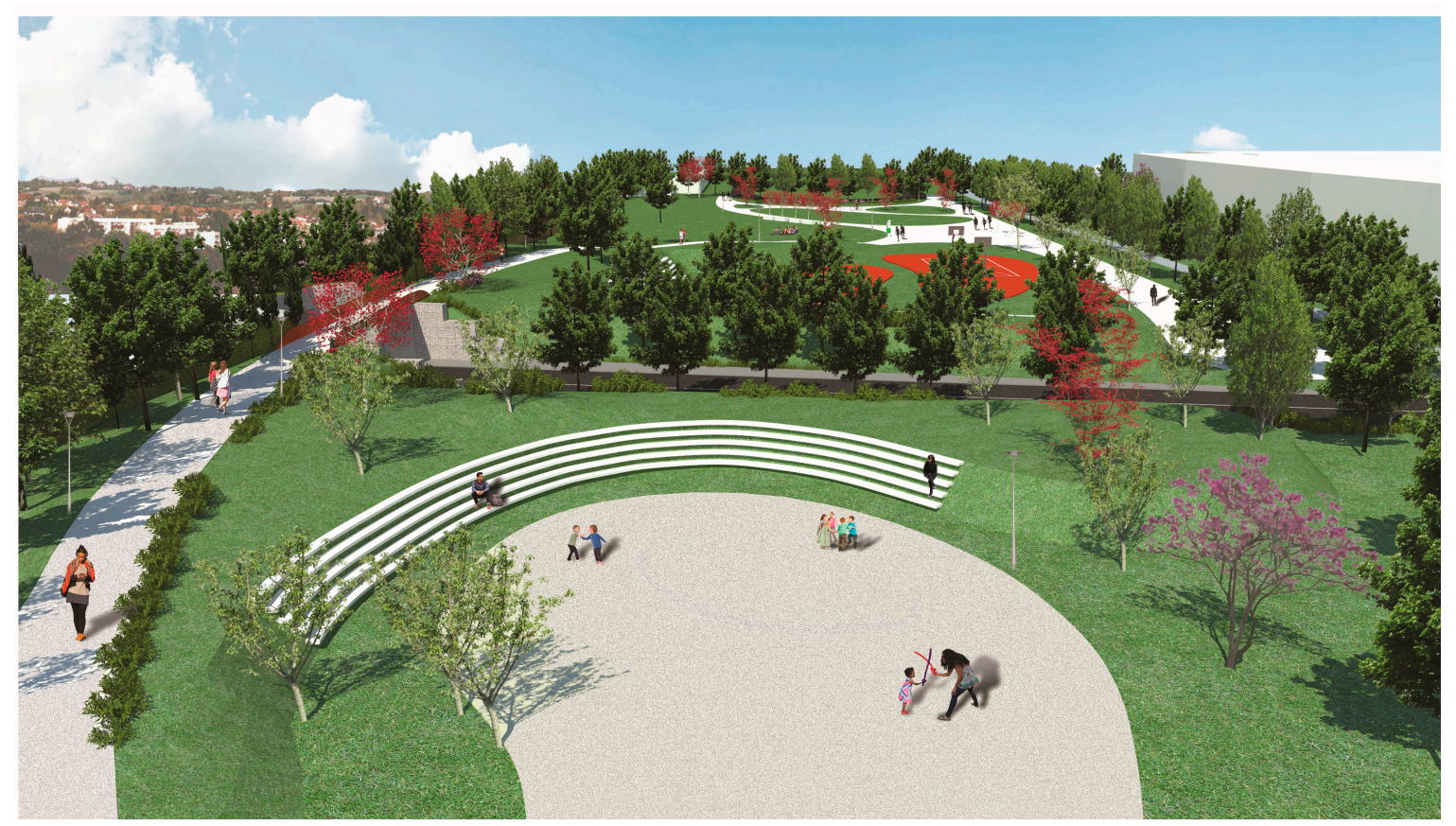

Figure 10. Overview. 
Author Contributions: Maria Pia Calabrò conceived and designed the experiments; Maria Pia Calabrò and Alessandro Buffi performed the experiments in Grasshopper; Maria Pia Calabrò analyzed the data; Fabio Bianconi, Maria Pia Calabrò and Marco Filippucci contributed reagents/materials/analysis tools; Fabio Bianconi and Marco Filippucci contributed to writing the introduction; Maria Pia Calabrò has written the central part of the paper.

Conflicts of Interest: The authors declare no conflict of interest.

\section{References and Note}

1. De Rubertis, R. Il Disegno dell'Architettura; Carocci: Roma, Italia, 2002; p. 11, ISBN: 9788843025176.

2. Coppo, D. Disegno e Immagine Della Città Nell'ottocento; Università Degli Studi di Trieste: Trieste, Italia, 1990.

3. Rai Cultura Network. Bodei, R. I Sensi Umani. Available online: http://www.filosofia.rai.it/articoli/remobodei-i-sensi-umani/4466/default.aspx (accessed on 15 november 2017).

4. Arnheim, R. Visual Thinking; University of California Press: Berkeley, CA, USA, 1969; p. 81, ISBN 9780520242265.

5. Kepes, G. Language of Vision; Paul Theobald: Chicago, IL, USA, 1944; p. 17, ISBNJ: 0-486-28650-9

6. Arnheim, R. The Dynamics of Architectural Form; University of California Press: Los Angeles, CA, USA, 1977; p. 128, ISBN: 0520035518.

7. Euclid Incardona, F.; Liquori, A.M.; Giannoli, G.I. (Eds.) Ottica: Immagini di una Teoria Della Visione; Di Renzo: Roma, Italia, 2011; ISBN 9788883232626.

8. Panofsky, E. Die Perspektive als Symzbolische Form; Teubner: Leipzig-Berlin, Germany, 1927; p. 54, ISBN 9783596147649

9. Scully, V. The Earth, the Temple and the Gods: Greek Sacred Architecture; Yale University Press: London, UK, 2013.

10. Vernant, J.P. Mythe et pensée chez les Grecs. Études de psychologie historique. Revue des Études Anciennes 1966, 68, 158-161.

11. Farinelli, F.; Geografia. Un'introduzione ai Modelli del Mondo; Einaudi: Torino, Italia, 2003; p. 198, ISBN 9788806160203.

12. Doxiadis, C.; Tyrwhitt, J. Architectural Space in Ancient Greece; Translated and Edited by Jaque-Line Tyrwhitt, J.-L., Ed.; MIT Press: Cambridge, UK, 1972; ISBN 0262540304.

13. Le Corbusier. Vers une Architecture Éditions Crès; Collection de "L’Esprit Nouveau": Paris, France, 1923, ISBN 2707304271

14. Aristotle De Anima, II. 7 418a27-28.

15. Gregoric, P. Aristotle on the Common Sense; Oxford Unversity Press: Oxford, UK, 2007; ISBN 9780191608490.

16. Boscarol, M.M. Le Dottrine del Colore di Aristotele, in Storia Della Sensazione del Colore. Available online: http://www.boscarol.com/ (accessed on 15 november 2017.

17. Alexander, C. Notes on the Synthesis of Urban Form; Basic Books: Milan, Italy, 1964; p. 194, ISBN 0674627512

18. Beghini, A. Il Concetto di Spazio, Nuovadidattica, 2011; p. 11. Available online: https://www.nuovadidattica.net/ didattica/pdf_didattica/spaziobeghini.html (accessed on 15 November 2017).

19. Lynch, K.; Rodwin, L. A Theory of urban form. Ekistics 1959, 7, 479-486.

20. Lynch, K. The Image of the City; Harvard-MIT Joint Center for Urban Studies Series: Boston, MA, USA, 1960, ISBN 9780262620017.

21. Barthes, R. Semiologia e urbanistica. Op. Cit. 1967, 9, 13.

22. Panofsky E. Meaning in the Visual Arts; Anchor Books: New York, NY, USA, 1955, ISBN 9780226645513.

23. Bitti V., La città non si dissolve nell'aria: Metafore urbane e nuovi media. In È Successo Qualcosa Alla Città; Manuale di Antropologia Urbana, Donzelli: Roma, Italy, 2010; ISBN 9788860364623.

24. Bigi N., Because Lynch is still relevant. Dialoghi Internazionali 2011, 16, 119-121.

25. Bianconi, F.; Filippucci, M. Monumenti della modernità. Infrastrutture e paesaggio nell'Umbria del XX secolo. AID MONUMENTS. Conoscere progettare ricostruire. In Proceedings of the AID MONUMENTS. 1st International Conference on Architecture and Engineering for the Defense of the Monuments, Conforti, C., Gusella, V., Eds.; Arachne: Rome, Italy, 2014; Volume I, pp. 252-259, ISBN 978-88-548-6506-8.

26. Battista, C. Frammentazione Ambientale, Connettività, Reti Ecologiche. Un Contributo Teorico e Metodologico con Particolare Riferimento Alla Fauna Selvatica; Assessorato Alle Politiche Ambientali, Agricoltura e Protezione Civile: Roma, Italia, 2004; ISBN 8890029765. 
27. De Rubertis, R.; Soletti, A. De Vulgari Architectura. Indagine Sui Luoghi Urbani Irrisolti; Officina: Roma, Italy, 2000; ISBN 10: 8887570027.

28. De Rubertis, R. La Città rimossa. Strumenti e Criteri per L'indagine e la Riqualificazione dei Margini Urbani Degradati; Officina: Roma, Italia, 2002; ISBN-13: 9788887570441.

29. Clément, G. Manifeste du Tiers Paysage; Éditions Sujet/Objet: Paris, France, 2004; ISBN: 2845342365.

30. Brown, J.; Mitchell, N.; Beresford, M. Protected landscapes: A conservation approach that links nature, culture and community. In The Protected Landscape Approach: Linking Nature, Culture and Community; Brown, J.; Mitchell, N.; Beresford, M., Eds.; GInternational Union for Conservation of Nature: Gland, Switzerland; Cambridge, UK, 2005; pp. 3-18, ISBN: 9782831707976.

31. De Fiore, G. Appunti di Viaggio, in Immagine Della Città Europea; Volta, V., Ed.; Tamellini: Legnago, Italy, 2005.

32. Farina, A. The cultural landscape as a model for the integration of ecology and economics. Bioscience 2000, 50, 313-320.

33. Buzan, T. Le Mappe Mentali e le Relazioni Personali; Frassinelli: Milano, Italy, 2008; ISBN 9788876848520

34. Tedeschi, A. Aad_Algorithms Aided Design, Parametric Strategies Using Grasshopper, 1st ed.; Editions Le Penseur: Brienza, Italy, 2014; ISBN 978-88-95315-30-0.

(C) 2017 by the authors. Licensee MDPI, Basel, Switzerland. This article is an open access article distributed under the terms and conditions of the Creative Commons Attribution (CC BY) license (http://creativecommons.org/licenses/by/4.0/). 